\title{
Virtual Reality Technology Based Vocational Education Study
}

\author{
Yanrong Ouyang \\ Wuhan Mechanical College, Wuhan, 430075, China \\ yanrong_ou@163.com
}

\begin{abstract}
Virtual laboratory is the object of this article. Virtual reality technology can benefit the education of vocational school. Here, proposed to use virtual reality (VR) technology, multimedia technology and network technology in vocational school, which can reduce the cost of semi-physical virtual simulation equipment, such as Helmet-Mounted Display.
\end{abstract}

Keywords: virtual reality; virtual laboratory; vocational education.

\section{Introduction}

VR technology is useful for displaying the teaching content vividly and introducing modern information and communication technologies into teaching, experiments and practical training. VR technology is helpful for adjusting the virtual content to following the development of equipment. The students can benefit from VR to master knowledge and skills. The teaching process is optimized and the teaching quality is improved.

With the rapid development of information, the equipment is more and more complex. VR technology has wide range of applications in vocational education. Firstly, the competition in information age is education competition mainly. Various positions need higher talent level of knowledge and professional technology. Thus, students of information age are needed to be good comprehensive quality and innovative thought. Secondly, graduated students are needed to increase proficiency. Except for academic qualifications, the students are needed more operation skills by enterprises. Thirdly, the gap of education funding between demand and investment is huge. Enterprises' equipments are upgrading day by day, and the teaching equipment is falling behind. VR technology can solve this problem effectively.

Modern education technology, including VR technology, multimedia technology, network technology, are introduced into vocational classes, which is helpful to show various equipment and virtual training environment that is impossible to be used in traditional teaching mode.

\section{Achievable target of VR technology in vocational class}

VR system is consist of images / graphics identification and generation system, sound/ tactile generation and identification system, network and communication system, artificial intelligence system, and sensor system. Applying VR technology in vocational education and training is giant developing. As far as vocational education theory, the students interact and influence VR environment mutually. VR environment creates "autonomous learning" environment and then students achieve new knowledge, skills, learning styles through their interaction with information and environment. Conversely, traditional learning style is "promoting learning by teaching". There are four benefits applying VR technology in vocational education.

\subsection{Mining the school's potential resource}

Importing VR technology improves vocational education environment, improves the amount of total students, and more students can be enrolled into vocational schools.

\subsection{Construction daily training base}

Multimedia technology, combination of hardware-in-loop simulation and virtual reality are utilized to build a virtual modern training base. The "equipment" or "parts" are mainly "virtual". What's more, "virtual" equipments can be upgraded according to the development of real equipments. 


\subsection{Construction digital campus}

VR technology is connected with ultra-high speed data transmission, mass data storage, distributed and parallel data processing. Applying VR technology accelerates the information construction of vocational school.

\subsection{Developing virtual teaching}

The classroom expands to invisible teaching space as virtual classroom and virtual school. VR technology can be used as removable distance learning e-learning site. Distant education is based on interactive distance learning course catalogs and websites, LAN tool linking to Campus Web sites, providing open and vocational skills training opportunity.

\section{Influences on the teaching of vocational schools}

\subsection{Changing teaching concept}

Modern teaching method changed traditional classroom teaching method to enlightening method, pursuing the cooperative of teaching and learning, empowering student learning initiative. Virtual reality helps creating this kind of environment. Teacher-centered lecturing will be changed to learner-centered individualized teaching, and achieve co-operative learning and self-inquiry in VR environment.

\subsection{Changing the content}

The experimental level of repair skill and abilities is trained in experiment. In experimental teaching of traditional, the content focuses on the discipline of theory and the method of using equipment and instruments, from which students draw conclusions and summarize the law.

The educational technologies develop and merge with interactive multimedia technologies. Multimedia information is with a variety of forms. Three dimensional virtual realities is an important form to descript abstract and general concepts and principles beside from words and voice.

Application of virtual reality will lead to internal changes in the structure of teaching content. The internal structure is the knowledge structure of the subject and the logical relationship of knowledge, which is information source of embedded intelligence.

Combined with virtual reality technologies, multimedia information broadcast through networked hyperlink to organize and display content, build knowledge structures, which is close to s of human cognition characteristic. The nonlinear structure of virtual reality facilitates students to associate obtained knowledge and gain new knowledge in divergent mind.

\subsection{Changing teaching method}

VR helps heuristic teaching. Compared with traditional of slide, and projected film and CAI courseware, VR provides multiple senses stimulus intuitively. Audio-visual material is broadcasted directly. The human-computer interaction reacts with outside by vision, audition, and tactile. Students gain the knowledge points by lively intuitive thinking material.

Discovery teaching is a kind of problem-centered teaching. With VR technology, students access environment with questions, which targeted and heuristic virtual environment.

In VR teaching, students will benefit from good human-computer interaction. It allows students' errors and mistakes. Students should think the causes and consequences of errors. What's more, they are trying to solve the met problems.

VR teaching is free from location and space; students can share the virtual space with teachers remotely, and cooperate and complete certain projects or training with others.

Animation can be used in VR teaching, which shows abstract concepts and principles, vividly process of a real experiment. It creates real learning situations to help students accessing exemplary knowledge and grasping the essence of concepts.

\section{Designing of VR teaching}

For vocational students, the practice is important than other kinds of students. Normal labs are designed to verify the theory and expand the curriculum theory. Students understand 
the theory deeper. Experiments foster innovative ideas and rigorous style of study. Professional courses cultivate students' practical ability. The ability for actual working positions should be from workshop-style training centers. New equipments are difficult to be assigned to vocational schools. In order to renew the equipments timely and reduce the needs of resources, VR technology is needed. VR technology protects expensive real equipment, reducing the risk of misuse, shortening the time to occupy devices.

In the session of operational training, we set up the teaching mode. It's "theory-experiment (theory Validation) - practice (virtual) - practice (technical ability)" teaching mode. VRDL (Virtual Reality Drill Library) is an important session. This mode is a bridge between common laboratory and training center. It's an advanced and combined training mode, and the investments for equipment and materials are reduced. It's easy to extend and change the VR training projects, and particularly suitable for equipment teaching.

\section{Conclusion}

Virtual laboratory is Scalable which is a distributed multimedia system based on high-speed computer networks. Adding, deleting or modifying some emulators is free from interrupting the entire system. The collaborative simulators can be distributed arbitrary positions. By local area networks or telecommunication systems, the distributed simulators can participate in a same project at the same time, with more intuitive, immersive simulation effects.

It's proved that virtual reality technology can benefit the education of vocational school. Virtual Reality (VR) technology, multimedia technology and network technology in vocational school, reduce the cost of semi-physical virtual simulation equipment and students benefit from VR to master knowledge and skills.

\section{References}

[1] Yingli CAO, Huaihui LI, Rongjun CUI, Establishment and application of Virtual Lab in University Health Vocational Education, Computer CD Software and Applications, Vol. 13 (2011), p.248-249.

[2] Xin XU, Wei LIU, Theoretical discussion on application of VR-based Simulation technology in vocational education, Journal of Bohai University (Natural Science Edition), Vol. 28 (2007), p.70-72.

[3] Shubo LI, Theoretical Study on Application of Virtual Reality Technology in Vocational Education, Journal of Liaoning Higher Vocational, Vol.15 (2013) , p.13-15.

[4] Jinshan XING, On the multimedia in training the learning interests of students in vocational education, Journal of Nanchang College of Education, Vol. 26 (2011), p.75-76. 